POLLACK PERIODICA

An International Journal for Engineering and Information Sciences

DOI: $10.1556 / 606.2017 .12 .3 .9$

Vol. 12, No. 3, pp. 99-108 (2017)

www.akademiai.com

\title{
SALT CONTENT ANALYSIS OF HISTORIC MASONRIES WITH SEM
}

\author{
${ }^{1}$ Brigitta TÖRÖK, ${ }^{2}$ Adél LEN, ${ }^{3}$ Zoltán ORBÁN \\ ${ }^{1,2,3}$ Department of Civil Engineering, Faculty of Engineering and Information Technology \\ University of Pécs, Boszorkány u. 2, H-7624 Pécs, Hungary \\ e-mail: ${ }^{1}$ torok.brigitta@witch.mik.pte.hu, ${ }^{2}$ len.adel@mik.pte.hu, ${ }^{3}$ orbanz@mik.pte.hu \\ ${ }^{2}$ Neutron Spectroscopy Department, Hungarian Academy of Sciences \\ Wigner Research Centre for Physics, Konkoly-Thege 29-33, Budapest, Hungary
}

Received 6 January 2017; accepted 10 July 2017

\begin{abstract}
This paper presents a nonstandard experimental procedure for detection of the presence of salts in building materials. The proposed tests helped modeling the deterioration of specific historical building materials caused by salts. The specimens were subject to visual survey and scanning electron microscope analyses, after submerging them in salt solutions. The results showed the damage of brick, cement based mortar and lime based mortar, caused by various concentrations of sulphate and chloride solutions. By this method various types of salt crystals could be identified. In cement and lime based mortars larger extents of salt deposits were found. A relevant difference between the control samples and the salt treated samples was observed.
\end{abstract}

Keywords: Historic masonries, Salt decay, scanning electron microscope

\section{Introduction}

The restoration of ancient cultural heritage buildings, their structural analysis, diagnosis and justification of their adopted strengthening solutions have proven to be an important and complex task that requires a multidisciplinary approach. Survey of existing structures and determination of their expected lifetime is highly important for owners so as to plan interventions more economically.

The easiest and most simple way of building survey is the visual inspection, which is the first step of an interdisciplinary analysis. Making a detailed note of defects on the spot is very useful and in most cases indispensable. Visual survey can be supplemented by determination of geometrical data measured by conventional devices and even by 
gathering some data in connection with the construction technology (e.g. type of structural materials).

If the mechanical characteristics of the typical components of masonries used in historical buildings (e.g. masonry brick or stone units, mortars) and their variability could be determined by using simple survey techniques, their safety assessment could be carried out in a more reliable and economical way.

Nevertheless, in order to optimize intervention measures on historical masonry buildings, it is necessary to know several structural and material characteristics that cannot be determined by using conventional analyses techniques. As the behavior of the structure depends on the mechanical, physical, and chemical properties of its constituent materials; it is therefore essential to carry out proper analyses.

In some cases, minor damage of buildings is unavoidable, to get appropriate information about the state of the structures, and the properties of specific building materials. A video endoscope analysis is usually carried out through a narrow drilled hole being a minor-destructive survey, therefore, it helps to find inhomogeneity and layers with different traits. To be able to determine some other important properties of the structural materials, samples can be subjected to Scanning Electron Microscope (SEM) analyses as an alternative. Although SEM does not damage specimens, masonries are slightly impaired during sampling [1].

Historical structures are exposed to several damaging factors. Physical, mechanical and chemical processes can cause damage in masonries. Deformation, vibration and strain may result in cracks. Some structures have sensibility to large variations of internal forces and stresses, like masonry arches. In case of bridges typical damage is often caused by the dynamic effects of traffic loading [2].

Erosion is also an important problem, caused by water, which repeatedly penetrates from the surface into the structure, and then evaporates. The transmission of water can cause several problems. When temperature decreases, water freezes in pores, which causes inner tension, then cracks. As a chemical effect, transmission of water potentiates the crystallization of salts. Another damaging effect is the acidic rain, which causes carbonation in building materials. The expansive action of the $\mathrm{SO}_{4}{ }^{2-}$ and $\mathrm{H}^{+}$ions causes the detachment of the cement and mortar grains from the matrix by penetrating into the pore solution, decreasing the $\mathrm{pH}$ and loosening the microstructure [3].

The presence of harmful salts is a crucial problem of historical monuments that must be examined narrowly. Methods to estimate the remaining life-time of structures exposed to acidic attack have been developed, however these methods lack modeling of parameters, because the damage does not manifest itself in the same way all the time. [4]. Therefore besides laboratory test methods there is a need of performing research work at the site. This paper deals with the analysis of salt content in historical masonry materials.

Masonries exposed to environmental effects are often affected by different kinds of salts. What is more, building materials often contain salts from the time of the construction. The presences of salts cause volume expansion (surrosion), which results in strength decrease and damage of materials. Identification of the exact type of harmful salts is of high importance to be able to find the best way of renovation. 
The aim of this study was to verify in what measure could the SEM, as a nondestructive method contribute to determine the amount and type of different kinds of salts in historical masonry building materials.

\section{Materials and methods}

Following to salt solution steeping test, lime based mortar, cement based mortar, brick samples and their control samples were analyzed. The basis of the experiment was the MSZ EN 12370:2000 standard.

Four different kinds of salt solutions were made. 14 wt $\% \quad \mathrm{Na}_{2} \mathrm{SO}_{4} \times 10 \mathrm{H}_{2} \mathrm{O}$ (mirabilite) and $\mathrm{NaCl}$ (halite), and the $28 \mathrm{wt} \%$ variant of both solutions. The samples were taken from existing structures, instead of the MSZ EN 12370:2000 standard recommendation that uses cubes $(5 \times 5 \times 5 \mathrm{~cm})$. The aim was to demonstrate the extent of salt damage, instead of the measure of the salt (and water) intake of the samples. Using new, standard cubes for these analyses would make impossible to take into consideration the properties of the historical building materials, such as technological characteristics and other impacts from different sources [4], [5].

The analyzed brick sample is a typical $19^{\text {th }}$ Century building material, signed with ' $\mathrm{T}$ ', referring to the Tolna County brickworks. Mortar samples were taken from two different buildings. The cement based mortar was taken from a railway bridge on the $43^{\text {th }}$ line of the Hungarian Railways (section $1017+18$ hsz.), which was built in 1895 . The lime based mortar was taken from a temple ruin and dates back to the $15^{\text {th }}$ Century.

The samples were prepared; they were broken into pieces with approximately the same volume. Following that, they were dried until their weight has become constant. Every sample - except the control ones signed with $1.1 ; 2.1 ; 3.1$. - were steeped for 24 hours. Samples were kept in laboratory conditions $\left(20^{\circ} \mathrm{C} \pm 2^{\circ} \mathrm{C}\right)$ during and after the imbibition process. After this, the samples were dried until their weight has become constant. At first, samples were analyzed visually. Variations of several features of the specimens were observed. Fig. 1 shows the samples before and after the salt treatment.

\section{Analysis with scanning electron microscope}

Table I contains the conclusions of the visual survey. The conclusions of the visual survey were refined by examining the images, taken by SEM.

The equipment used during this survey was a VEGA 3 S type SEM, equipped with a SE detector.

The analyses of the specimens were only possible following the proper adjustment of the SEM, what means an electron beam of only $11 \mathrm{kV}$, because of the lack of a conducting graphite or gold layer on the surface of the mortar samples. 


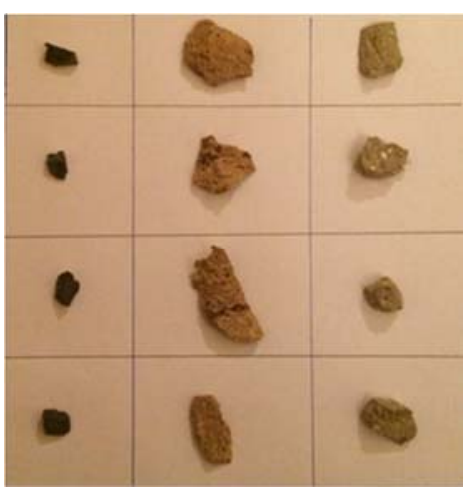

a)

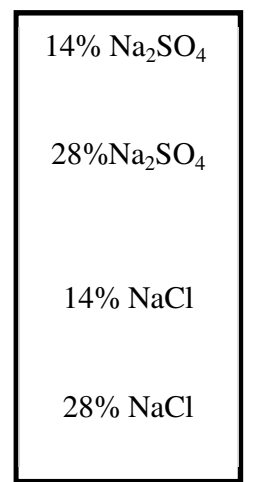

Fig. 1. Samples a) before and b) after the salt treatment

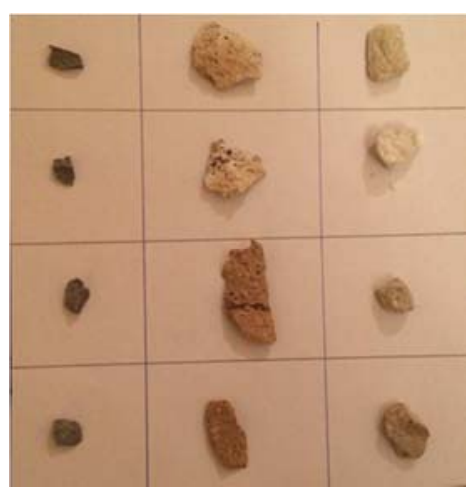

b)

Table I

Samples macroscopic analysis




Since the analyzed specimens were not conductors, during the measurement, being bombarded with electrons, the charge accumulated on their surface was higher for bigger high voltage values. As a solution, the analyses were carried out in shorter periods of time, and lower high voltage.

\section{Results and observations}

The phenomena of salt accumulation were visible mainly on the surface of the specimens. The differences of the crystal structure of the harmful salts were clearly visible and demonstrable. Table I gives the summary of visual inspection results of specimens after the exposure to salt solutions.

On the surface of the samples affected by sulphate, granular coarse crystals ('coralliferous') were seen; meanwhile the halite shows a typical body-centered cubic form [6].

In case of the sulphate, the connection between the concentration of the applied salt solution and the visible salt openings is not linear. On the surface of the specimens soaked in $28 \mathrm{wt} \%$ sulphate solution smaller salt openings can be found, compared to the samples imbibed in the dilute $14 \mathrm{wt} \%$ solution, which resulted in larger salt openings. The samples signed with 1.3 (Fig. 2); 2.3 (Fig. 3); 3.3 (Fig. 4) show a continuous crystal structure on their surface that fills up even the cracks on the specimens.

The interior structures of the materials were surveyed too; the crystallization within the porous system causes a considerable decrease in strength [7].

The duration of the steeping process lasted 24 hours that has not proven long enough to cause salt crystallization growth patterns in the inner parts of the specimens.

However the short-term exposure of the mortars and bricks to sodium chloride and sulphates in concentrations significantly higher than that of arising from acidic rain or other chemical attacks, simulated the surface layer damage in mortars, which is the source for further development of free cracks, as channels for water and chemicals penetration. The presence of salts, especially sulphates, is the cause of chemical reactions between the hydration products and salts, causing the damage of the bonding between the cement grains, additionally the chemical reaction products (e.g. monosulphates) - by a significant volume increase - are sources of further cracks inside the cement or mortar structure.

Fig. 2 and Fig. 3 show different properties, like porosity and mineral structure. Fig. 2. is a lime based mortar specimen, therefore more porous than the other specimen (Fig. 3.) and its surface is more homogeneous. The brick specimen (Fig. 3.) shows more cracks and irregularity on the surface. These differences show that useful information can be gained by using SEM.

Fig. 4 shows the cement based mortar imbibed in $28 \mathrm{wt} \% \mathrm{Na}_{2} \mathrm{SO}_{4}$ solution. The needle-like two micron sized crystals are assumed to be hydrous calcium aluminum monosulphate minerals, causing decrease in strength [8], [9]. 


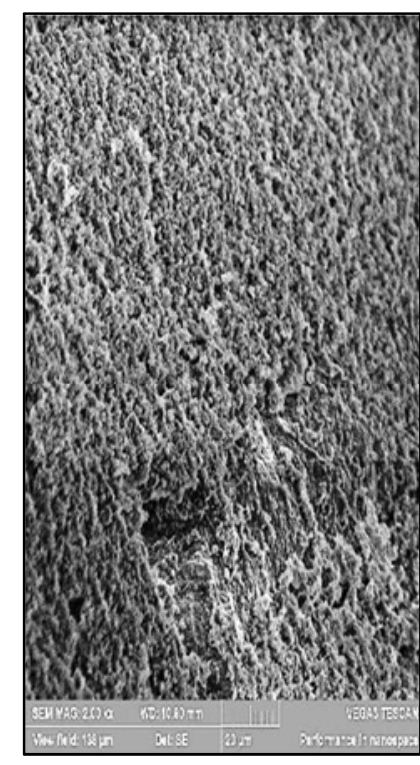

a)

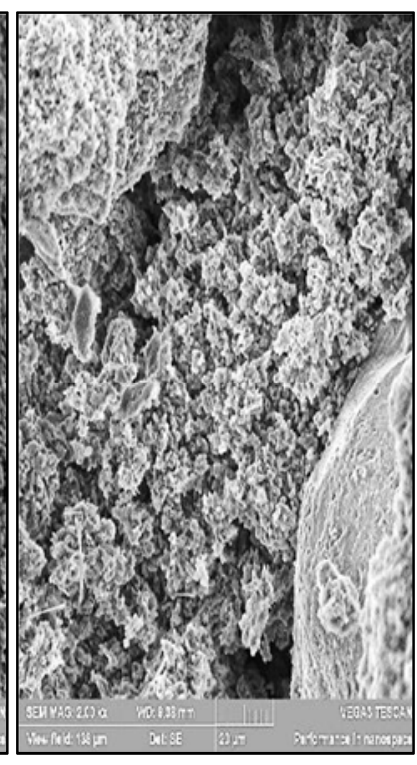

b)

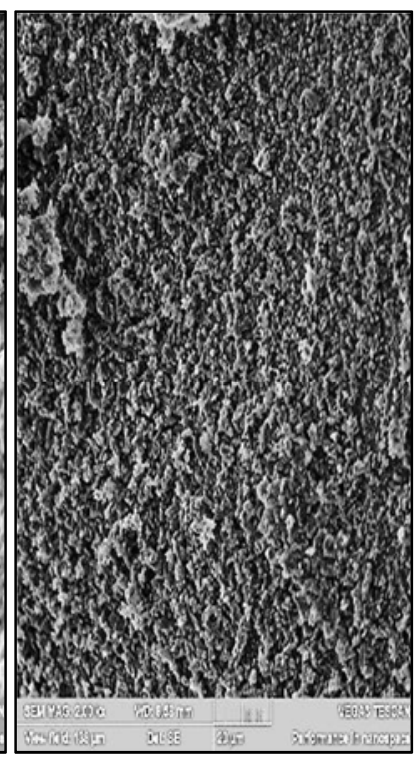

c)

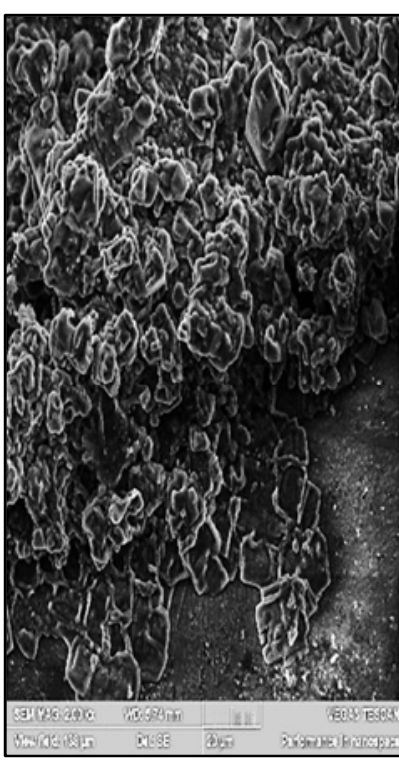

d)

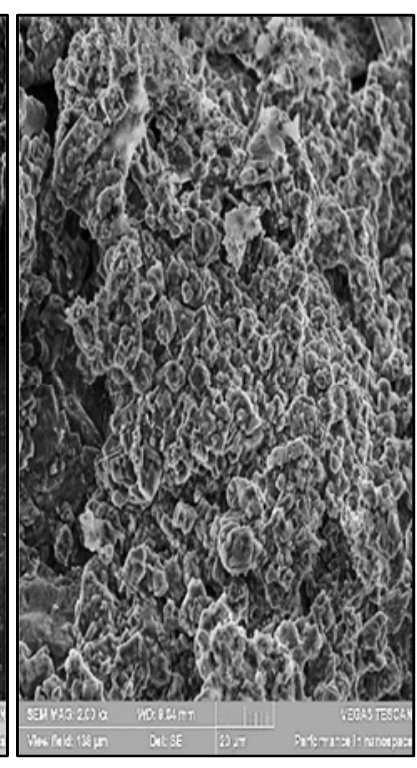

e)

Fig. 2. Lime based mortar analysis with SEM: a) control sample (1.1); b) sample steeped in salt solution $14 \mathrm{wt} \% \mathrm{Na} 2 \mathrm{SO} 4$ (1.2); c) sample steeped in salt solution $28 \mathrm{wt} \% \mathrm{Na} 2 \mathrm{SO} 4$ (1.3);

d) sample steeped in salt solution $14 \mathrm{wt} \% \mathrm{NaCl}(1.4)$; e) sample steeped in salt solution $28 \mathrm{wt} \% \mathrm{NaCl}(1.5)$ 


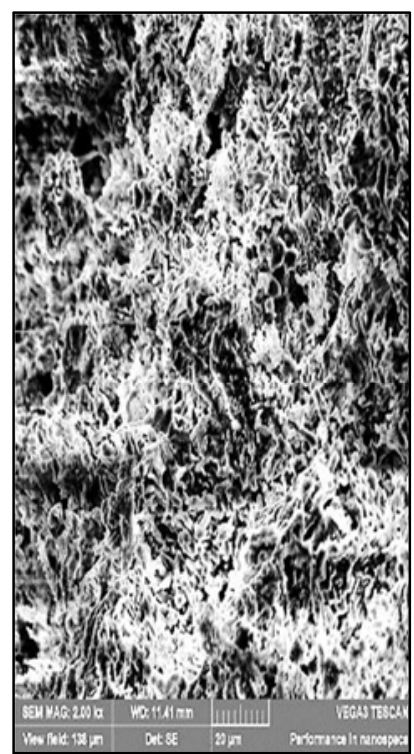

a)

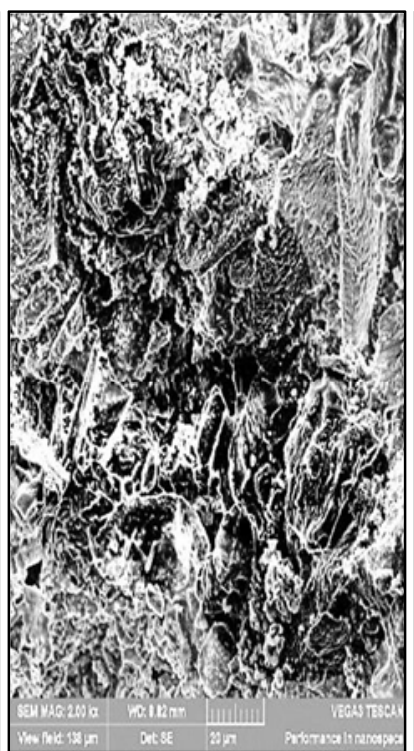

b)

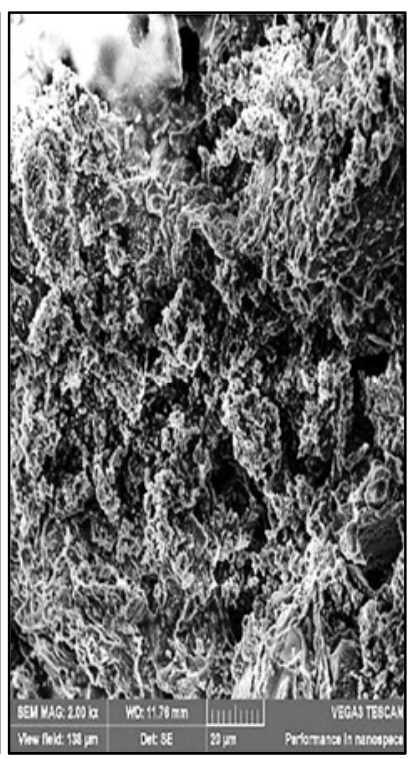

c)

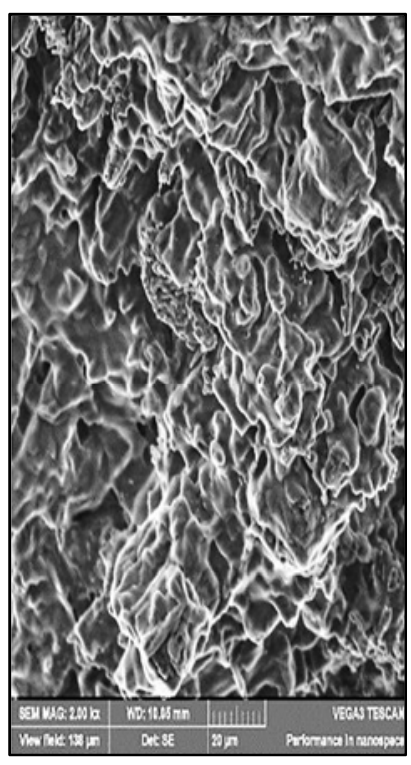

d)

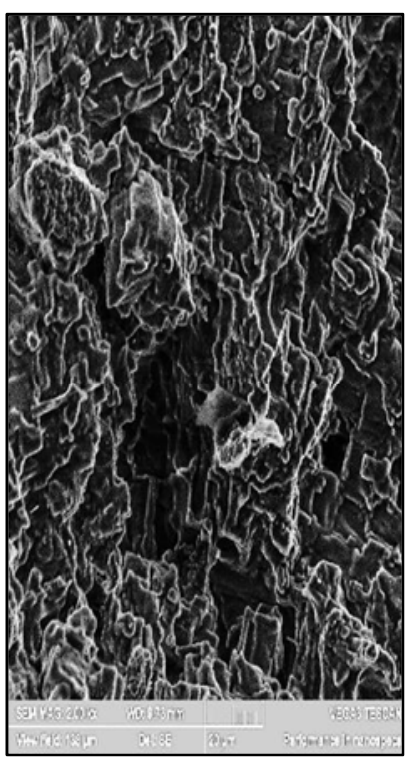

e)

Fig. 3. Brick analyses with SEM: a) control sample (2.1); b) sample steeped in salt solution 14 wt $\% \mathrm{Na}_{2} \mathrm{SO}_{4}(2.2) ;$ c) sample steeped in salt solution $28 \mathrm{wt} \% \mathrm{Na}_{2} \mathrm{SO}_{4}$ (2.3); d) sample steeped in salt solution $14 \mathrm{wt} \% \mathrm{NaCl}(2.4)$; e) sample steeped in salt solution $28 \mathrm{wt} \% \mathrm{NaCl}$ (2.5.) 


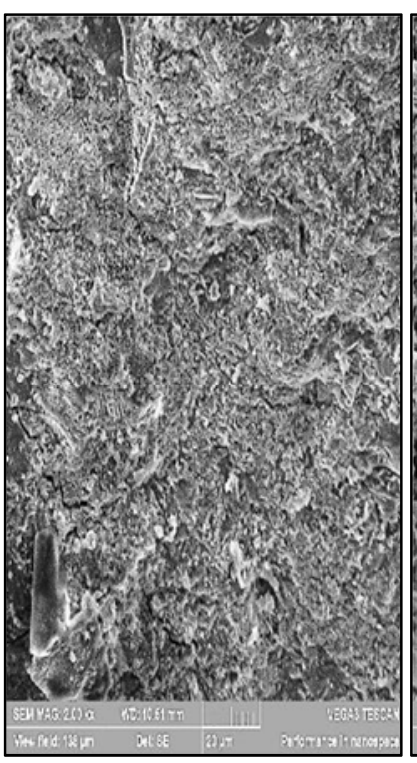

a)



b)



c)

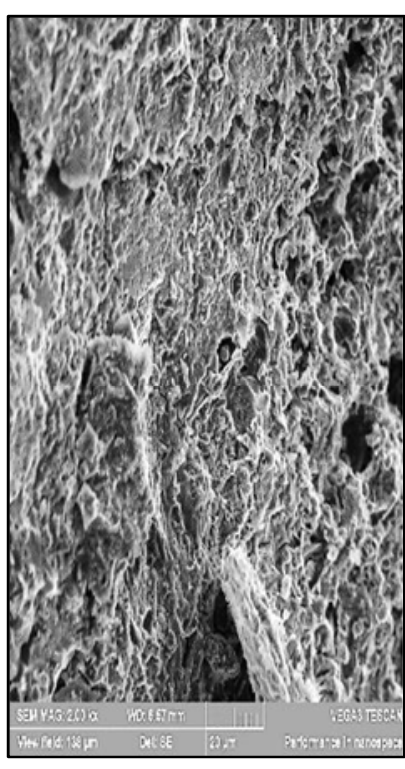

d)

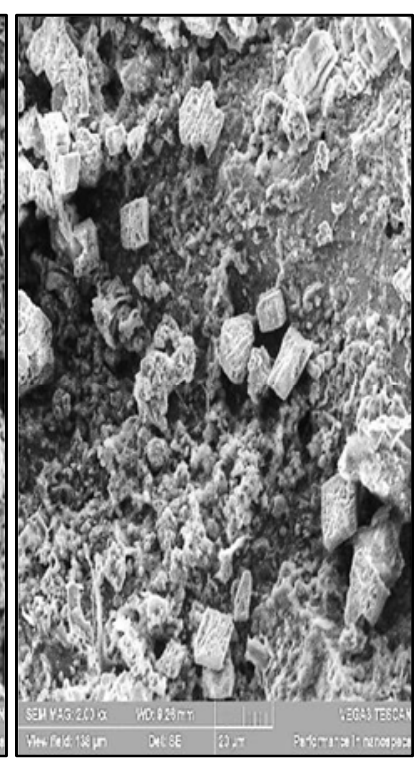

e)

Fig. 4. Cement based mortar analyses with SEM: a) control sample (3.1); b) sample steeped in salt solution $14 \mathrm{wt} \% \mathrm{Na}_{2} \mathrm{SO}_{4}$ (3.2); c) sample steeped in salt solution $28 \mathrm{wt} \% \mathrm{Na}_{2} \mathrm{SO}_{4}$ (3.3);

d) sample steeped in salt solution $14 \mathrm{wt} \% \mathrm{NaCl}(3.4)$; e) sample steeped in salt solution $28 \mathrm{wt} \%$ $\mathrm{NaCl}$ (3.5.) 
Fig. $5 a$ shows a specimen taken from masonry with large humidity. In this case, the size of the needle-like crystals is even larger, compared to that of the former sample.

Fig. 5 b and Fig. 5c shows the interior of the lime based mortar pickled in $14 \mathrm{wt} \%$ halite and $14 \mathrm{wt} \%$ mirabilite. Sodium sulphate and sodium chloride crystallization can be seen in the picture. The size of the crystals is rather small, but still visible.

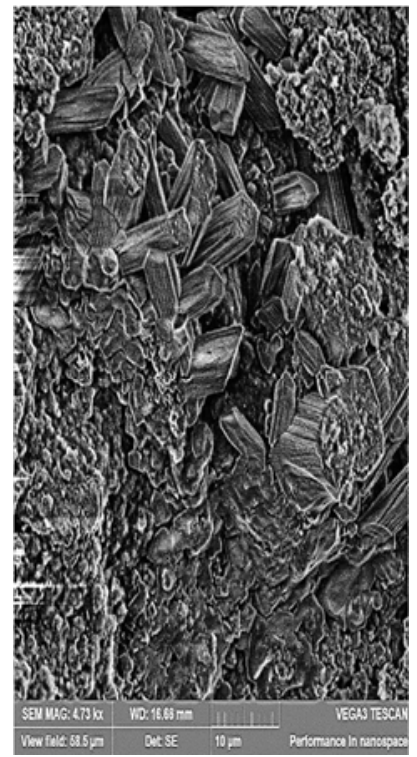

a)

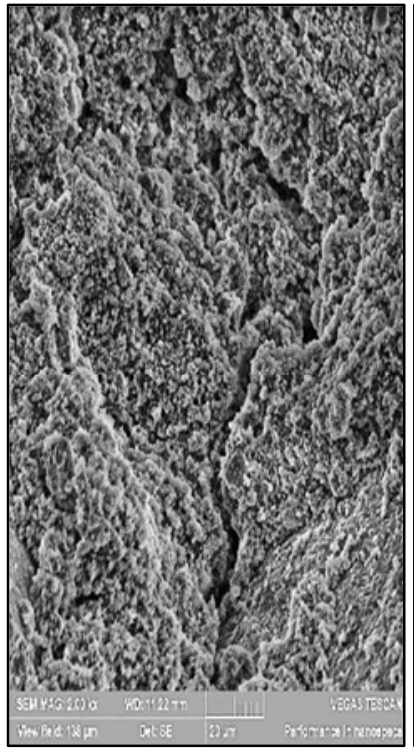

b)

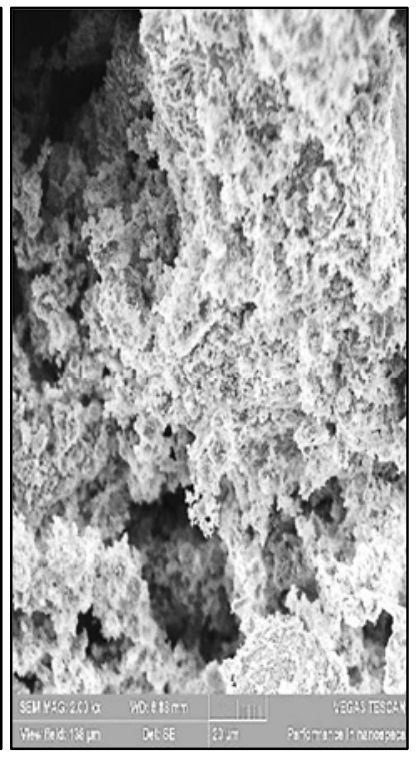

c)

Fig. 5. a) Cement based mortar specimen with needle-like crystal; interior of lime based mortar: b) sample steeped in salt solution $14 \mathrm{wt} \% \mathrm{NaCl}(1.4)$; c) sample steeped in salt solution $14 \mathrm{wt} \%$ $\mathrm{Na}_{2} \mathrm{SO}_{4}(1.2)$

\section{Conclusions}

The results of the analysis show that SEM analysis is an appropriate method to supplement the existing conventional diagnostic techniques, by which important information (e.g. salt crystals, cracks, pores) on the properties of the masonry materials can be obtained.

SEM was suitable to identify different types of salt crystals. However the evaluation of the salt content quantity requires further investigations.

Analysis of brick was more difficult task because of its homogenous structure and compactness. Salt crystals could only be seen on the surface of the specimens.

In case of non-conductive specimens, the suitable magnification used by SEM (2000x, 5000x) proved to be appropriate to analyze salt decay of historic masonries. 


\section{References}

[1] Orban Z. Increasing the reliability of the assessment of masonry arch bridges by nondestructive testing, Pollack Periodica, Vol. 1, No. 3, 2006, pp. 45-56.

[2] Orban Z. Assessment and lifetime expectancy of historical masonry arch bridges, Pollack Periodica, Vol. 9, No. 1, 2014, pp. 7-16.

[3] Jo B. W., Sikandar M. A., Chakraborty S., Baloch Z. Investigation of the acid and sulfate resistance performances of hydrogen-rich water based mortars, Construction and Building Materials, Vol. 137, 2017, pp. 1-11.

[4] Santhanam M., Cohen M. D., Olek J. Sulfate attack research - whither now? Cement and Concrete Research, Vol. 31, 2001, pp. 845-851.

[5] MSZ EN 12370:2000, Natural stone test methods, Determination of resistance to salt crystallization, 2000.

[6] Lubelli B., van Hees R. P. J. Effectiveness of crystallization inhibitors in preventing salt damage in building materials, Journal of Cultural Heritage, Vol. 8, No. 2, 2007, pp. 223-234

[7] Gentilini C., Franzoni E., Bandini S., Nobile L. Effect of salt crystallization on the shear behavior of masonry walls: An experimental study, Construction and Building Materials, Vol. 37, 2012, pp. 181-189.

[8] Stuztman P. E. Scanning electron microscopy in concrete petrography, Proceedings on Workshop on the Role of Calcium Hydroxide in Concrete, (Eds.) J. Skalny, J. Gebauer and I. Odler, Anna Maria Island, Florida, 1-3 November 2000, Materials Science of Concrete, Special Volume, 2001, pp. 59-72.

[9] Irassar E. F., Bonavetti V. L., Gonzalez M. Microstructural study of sulfate attack on ordinary and limestone, Portland cements at ambient temperature, Cement and Concrete Research, Vol. 33, No. 1, 2003, pp. 31-41. 